\title{
Search for blood or water is influenced by Borrelia burgdorferi in Ixodes ricinus
}

\author{
Coralie Herrmann ${ }^{*}$ and Lise Gern ${ }^{*}$
}

\begin{abstract}
An increasing number of studies suggest that vector-borne parasites are able to alter phenotypic traits in their arthropod vectors so that microorganism transmission is enhanced. This review documents this phenomenon, which occurs between Borrelia burgdorferi bacteria, the causative agents of Lyme borreliosis, and their tick vectors belonging to the Ixodes ricinus complex. It also reviews the influence of other tick-borne pathogens on these ticks. Ticks belonging to the Ixodes ricinus complex benefit from Borrelia infection by an increased lifespan (more fat and more resistance to desiccation) and by an increased questing period (less need to move to the litter zone to rehydrate), which enhances tick chances to find a host and to subsequently transmit the pathogens.
\end{abstract}

Keywords: Ixodes ticks, Phenotypic traits modification, Vector manipulation, Water balance, Blood meal, Borrelia burgdorferi

\section{Background}

The idea that a parasite can modify the phenotype of its host by changing the host perception of the environment and/or behaviour in order to complete its transmission cycle is intriguing. This phenomenon is well established and documented in hundreds of distinct host-parasite associations in all major phyla of living organisms [1,2]. While most of the known cases involve only subtle modifications in host phenotypes, some are doubtlessly spectacular. For vector-borne pathogens, the best-known examples involve pathogens transmitted by bloodsucking insects taking short blood meals on multiple hosts such as mosquitoes, sand flies, or tsetse flies. In such cases, manipulation usually consists of modifying vector behaviour so that the number of bitten hosts (and thereby infected hosts) is increased using strategies such as higher biting rates, shortened blood meals, a longer lifespan, etc. [3-5]. Unlike haematophagous insects, hard ticks feed for days (Figure 1) [6] and transmission of tick-borne parasites often needs some time after the beginning of tick attachment to occur (i.e. several hours), as for example the transmission of the agents of Lyme borreliosis (Borrelia burgdorferi sensu lato (s.l.)) by the European vector Ixodes ricinus [7,8]. Unlike insect-borne

\footnotetext{
* Correspondence: coralie.herrmann@unine.ch; lise.gern@unine.ch Institute of Biology, Eco-Epidemiology Laboratory, University of Neuchâtel, Emile-Argand 11, 2000 Neuchâtel, Switzerland
}

parasites, tick-borne parasites cannot increase the number of hosts encountered by their vectors during their life cycle (Figure 1) and other mechanisms have to intervene. Moreover, although finding a host is crucial for any haematophagous arthropod, ticks such as I. ricinus have an additional need that governs their behaviour and life cycle: maintaining their water balance. This need is particularly important for ticks because their parasitic life is very short (three blood meals, each of them taken over a few days) compared to their lifespan that extends over many years, spent in the environment (Figure 1). Maintaining a water balance is not compatible with hostfinding behaviour and is even detrimental to host-finding success. Therefore tick-borne parasites could be expected to influence tick behaviour in such a way as to maximise host-finding success in order to be transmitted.

\section{Review}

The search for blood

I. ricinus is a generalist tick that feeds on more than 300 different vertebrate species ranging from mammals to reptiles or birds [9]. It finds its vertebrate host while questing, i.e. waiting on low vegetation with its first pair of legs outstretched in the air. When a vertebrate host brushes the spot where the tick is waiting, the arthropod grabs the passing host, climbs onto it, and takes a blood meal. While questing for a host, ticks are often exposed 


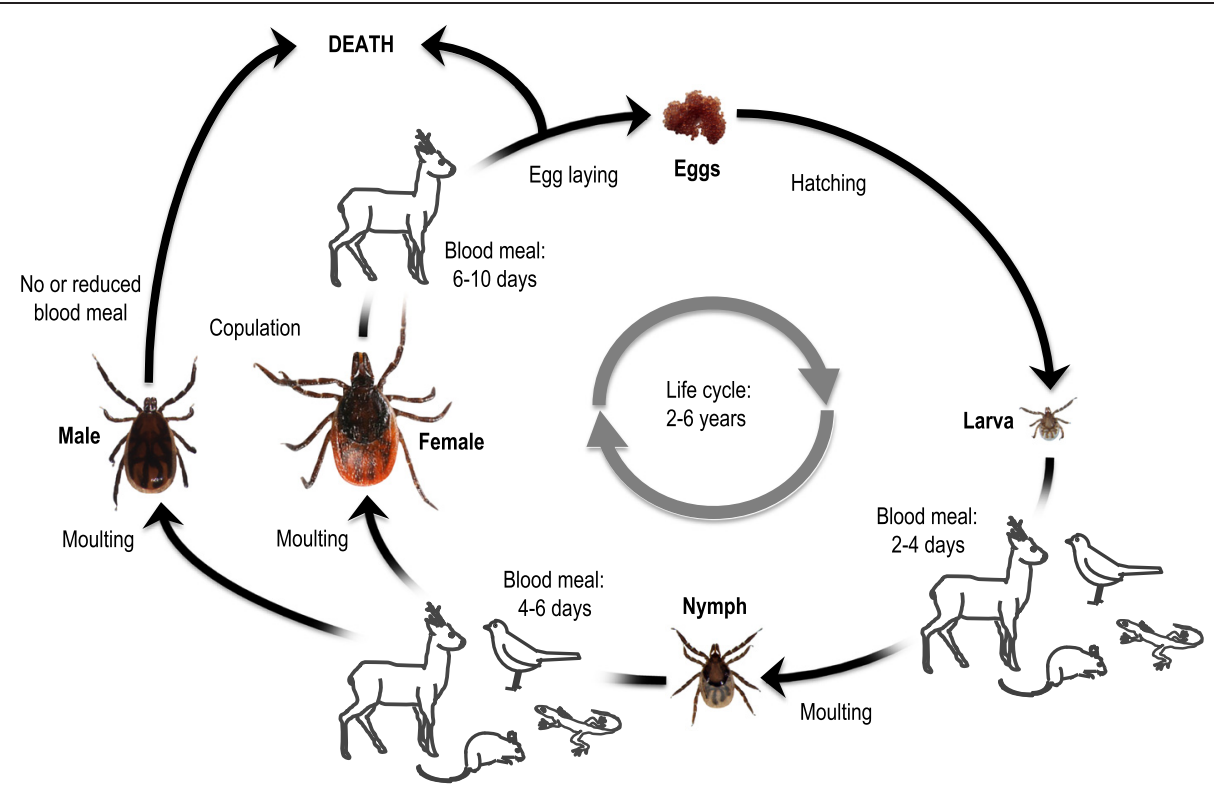

Figure 1 I. ricinus life cycle. I. ricinus is a three-host tick of which each stage, i.e. larva, nymph and adult female (adult males may take a small blood meal but do not fully engorge), feeds on a different vertebrate host. I. ricinus ticks parasitize a wide range of hosts, i.e. more than 300 different vertebrate species [9]. Immature ticks particularly infest rodents such as Apodemus flavicollis, Myodes glareolus and Sciurus vulgaris [32,70-73]. Immature ticks also feed on ground-foraging birds (such as Turdus spp), lizards and artiodactyls [9,74]. Adults mainly feed on larger mammals, but are usually outnumbered by immature ticks on such hosts [75]. I. ricinus does not show host specificity and the most important determinants of host choice are host habitat and behaviour, microclimate conditions [32], and questing height of the different tick stages. Larvae and nymphs usually stay closer to the ground, i.e. they are predominantly observed between 0 to $30 \mathrm{~cm}$ and 30 to $70 \mathrm{~cm}$, respectively [76,77], probably because they are more sensitive to ambient humidity than mature stages due to their high surface area to volume ratio [32]. Male and female adults are observed higher up on the vegetation, usually 60 to $80 \mathrm{~cm}$ above the ground, but they may be found higher than $1.5 \mathrm{~m}$ depending on the surrounding vegetation [76,77] (Tick pictures by N. Tonetti; Host pictures by P.-F. Humair and L. Gern).

to unfavourable moisture conditions and they frequently interrupt their questing, and move to the litter zone. There they are quiescent in a humid atmosphere where they rehydrate [10]. This behaviour shortens questing periods and thereby reduces tick's chances to find a host and transmit microorganisms.

\section{The search for water}

I. ricinus, like other terrestrial arthropods, needs to maintain its water balance in an environment whose relative humidity $(\mathrm{RH})$ is often below its comfort threshold (situated between 86 to $96 \% \mathrm{RH}$ according to Lees [11]). When RH is below this threshold, the tick needs to minimise water loss and maximise active uptake of water vapour from the atmosphere [12]. I. ricinus loses water through the integument of its body surface when it is exposed to relatively dry conditions (transpiratory loss) [12] such as those that $I$. ricinus experiences on vegetation while questing for a host. In addition, $I$. ricinus loses water in the course of respiratory exchange via the tracheal system (respiratory loss) [12]. This occurs during mobility - when the tick ascends the vegetation to find a questing spot and later descends from the vegetation to reach a moister environment - since respiration increases when ticks move [13-15]. Water loss due to transpiration and respiration is compensated for by acquiring water from the environment. I. ricinus does not drink liquid water $[11,16,17]$, but rather extracts water vapour from the atmosphere $[11,12,18]$, in particular by active sorption [19]. In nature, the tick achieves this by periodically returning down to moist surroundings such as the litter layer $[10,11]$, as shown by dehydrated $I$. ricinus nymphs moving preferentially towards fully saturated air under laboratory conditions $[18,20]$.

Perret et al. [21] reported that the duration of questing depends on desiccating conditions: when conditions are less desiccating, ticks quest for longer periods before moving to the litter zone, which increases their chances to find a host. In experimental settings locomotion occurs primarily during darkness in both I. scapularis [22] and I. ricinus [21]. Such behaviour has been considered to be a means to minimise water loss (and energy costs to reabsorb it) by undertaking locomotion during less desiccating conditions coinciding with darkness [21].

\section{Seasonal questing activity}

Temperature, humidity and photoperiod shape $I$. ricinus behaviour and lifespan in nature. Hence, the host-finding activity of I. ricinus is greatly influenced by weather conditions and progress is governed by a seasonal pattern 
(Figure 2). During winter, ticks do not usually quest and are in the leaf litter or in the upper layers of the soil where temperatures are milder than on the vegetation [23,24]. The interaction between photoperiodicity and temperature appears to determine whether $I$. ricinus ticks are active or not during winter [25-27]. However, additional research is needed to disentangle the roles played by photoperiodicity and temperature on the winter physiology/behaviour of $I$. ricinus. I. ricinus usually displays questing activity from February-March to September-October, but importantly this depends on temperature [28]. In spring, I. ricinus usually quests for a host when temperature ranges between 7 and $24^{\circ} \mathrm{C}$ in Switzerland [28,29]. During warmer and drier months (i.e June, July and August), questing tick activity is reduced while it may reappear in autumn (Figure 2). This is mainly due to a new cohort of ticks that emerge [30] but is also partly due to ticks from the previous cohort that quit quiescence $[21,29,31]$. Variability in air humidity also regulates tick seasonal questing activity. It is known that $I$. ricinus displays little resistance to desiccation [11,28] and that $\mathrm{RH}$ needs to be above 70 to $80 \%$ to allow questing activity and survival [28]. Saturation deficit (SD) (a measure of the drying power of the atmosphere that depends on both temperature and $\mathrm{RH}$ [32]), influences the seasonal activity of $I$. ricinus. SD values that are lower than $5 \mathrm{mmHg}$ are favourable for I. ricinus questing activity and development, [21,33]. In fact, I. ricinus questing activity [33-35], duration of questing [21,31], and survival in nature $[29,31]$ are reduced when SD values are high. I. ricinus larvae are less tolerant of desiccation and therefore die earlier than nymphs under desiccating conditions [28]. In turn, I. ricinus nymphs are more affected by desiccating conditions (therefore suffering a higher death rate) than adults, as shown by the partial restoration of the questing adult population (but not of the questing nymph population) after each drought event in nature [31]. The lower resistance to desiccation observed in immature stages compared to adult stages $[11,28,31]$ is probably due to their smaller size, lower water content and a higher surface area to volume ratio (causing a proportionally higher water loss) than in adults [32]. Tick populations are most importantly exposed to high SD values in spring (the usual questing activity peak in continental Europe) and summer, and to a lesser extent in autumn. Accordingly, I. ricinus questing density is low when SD is high during spring and summer [29].

\section{Influence of climate on the geographic distribution of $I$. ricinus}

Climate change affects $I$. ricinus geographic distribution, as illustrated by the shifts observed during the last decade towards higher latitudes in its northern distributions in Sweden [36,37] and Norway [38], and towards

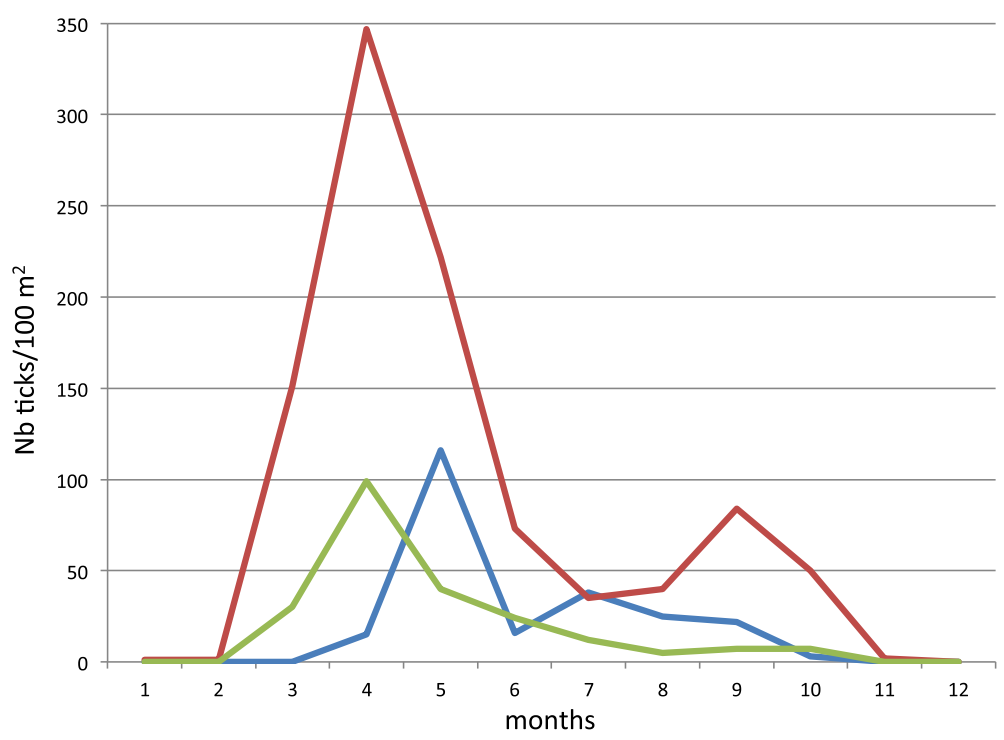

Figure 2 Stylised I. ricinus seasonal questing activity (based on data collected in the Neuchâtel area, Switzerland). In Switzerland, questing ticks may be collected as early as mid-February to early March [35]. In fact, questing I. ricinus ticks are active when the daily maximal temperature has reached $7^{\circ} \mathrm{C}$ over 5 days [29]. Adults and nymphs usually emerge first, followed by larvae. Questing tick density increases progressively as weather conditions get warmer [29] until peak density is recorded in spring, usually between April and June [34]. Questing density then decreases gradually due to decreasing numbers of unfed ticks still seeking a host and to increasingly drier weather conditions [29,31], so that I. ricinus ticks rarely quest during summer, except at higher altitudes where the climate is milder [33,34]. In autumn, when favourable conditions of temperature and humidity are back, a second peak of questing ticks may be observed [34]. However, the autumn peak is of lower intensity than the one observed in spring and is absent if weather conditions are unfavourable [29,31,34]. The last questing I. ricinus ticks are usually sampled in October or early November [34] as ticks return progressively to an inactive state during winter [26,78]. Larvae: green; nymphs: red; adults: blue. 
higher altitudes in the Czech Republic [39-41], Switzerland [34] and Norway [38]. Higher temperatures in spring and autumn extend the vegetation period and the season during which $I$. ricinus develops, allowing vegetation communities (and therefore vertebrates on which $I$. ricinus feeds) and tick populations to colonise and establish at higher latitudes [42] and altitudes [34,43]. In addition, climate change affects $I$. ricinus populations in areas where the tick is already established, notably influencing its seasonal questing activity [27,29], and seems to gradually extend I. ricinus seasonal activity as it uses milder winter periods for re-emerging and questing $[26,27]$.

\section{Energy in ticks}

Ticks consume energy (i.e. fat) while locating and ascending vegetation stems from which they quest for a host, and descending to moist conditions at the base of the vegetation where they restore their fluid content $[10,12,16,19]$. This energy is acquired through the single blood meal that is taken by each of the three developmental stages. Although the blood meal primarily consists of proteins (up to 95\%), the digestive products obtained during feeding are largely converted to, and stored as, fat (lipids) [44]. Lipids are stored in epithelial cells of the midgut $[45,46]$, and in the fat body of ticks (a diffuse organ of highly dispersed strands of cells adhering to the branches of the tracheal system and, occasionally, to other internal organs) [47]. As I. ricinus has no other energy sources, fat content declines over time between each blood meal $[30,36,48]$. Randolph and Storey [32] have demonstrated that ticks kept under dry conditions consume their fat twice as fast as those kept under wet conditions. In addition, a linear relationship between temperature and lipid consumption has been observed in male and female I. ricinus [49]. When weather conditions get drier [21,32], I. ricinus needs to move down the vegetation to rehydrate, more often consuming even more energy in the process. Hence, in I. ricinus, the rate of lipid consumption increases under unfavourable conditions of humidity [32] and temperature [49]. Accordingly, fat content reflects both the history of the tick stage and the energy reserves remaining for future use $[30,32]$.

In summary, I. ricinus has two basic and interconnected needs that govern its entire behaviour and life cycle: finding a host for blood feeding and maintaining its water balance. Finding the right balance between these two needs, which are rarely in agreement, is a real challenge for $I$. ricinus. To fulfil these needs, the tick consumes energy when it climbs up the vegetation to quest, and when it periodically moves down the vegetation to rehydrate in the litter layer.

\section{Modification of phenotypic traits of ticks by microorganisms}

Various studies have reported that bacteria and viruses may modify the traits of I. ricinus, I. persulcatus, I. scapularis and I. pacificus; the main tick species playing a role in the transmission of B. burgdorferi s.l. (Table 1). Even though it has been known for decades that I. ricinus is sensitive to humidity and that dehydrated ticks move preferentially towards a moister environment $[18,20]$, the influence of infection on tick tolerance to desiccation has been poorly investigated. Alekseev [50] has reported that $I$. persulcatus, the Asian vector of $B$. burgdorferi s.l., infected with the tick-borne encephalitis virus (TBEv) choose a higher questing height. Similarly, other authors have shown that Borrelia-infected I. scapularis [51], the North American vector of B. burgdorferi s.l., and I. persulcatus [52], also choose a higher questing height, which exposes ticks to more desiccating conditions. This suggests that TBEv- and Borrelia-infected ticks are less sensitive to a dry environment than uninfected ticks. In fact, it has been shown recently that Borrelia-infected $I$. ricinus nymphs have a lesser need to move towards a moist environment, which is favourable for their water balance, than uninfected nymphs [53]. When they are given the choice between dry and moist environments Borrelia-infected individuals stay where the RH levels are between 70 and $75 \%$ (corresponding to SD values of 6.2 to $5.2 \mathrm{mmHg}$ at room temperature, $\sim 23^{\circ} \mathrm{C}$ ), whereas uninfected ticks tend to move to a moister environment when SD reaches $4.4 \mathrm{mmHg}$ (corresponding to $80 \% \mathrm{RH}$ at $24^{\circ} \mathrm{C}$ ) in nature [28]. In this case, vector manipulation consists of increasing the tick's chances of finding a vertebrate host (and thereby transmitting the pathogen) by increasing questing time, i.e. by allowing the tick to quest for a longer time under desiccating conditions before returning to a moister environment, such as the litter layer, to rehydrate.

During winter months, ticks may be exposed to very cold weather and survival represents a challenge for them [54]. Interestingly, an increase in the survival under cold conditions of I. scapularis infected by Anaplasma phagocytophilum has been reported recently [55]. A. phagocytophilum has been shown to induce the production in ticks of an antifreeze glycoprotein protecting ticks from extreme cold. Similarly, extreme weather conditions during spring and summer involving high temperature and low RH not only influence questing activity [33-35] and duration of questing [21,31], but also survival of ticks in nature [29,31]. Recently, increased survival of I. ricinus under highly desiccating (hot and dry) conditions when infected by B. burgdorferi s.l. has been reported [56]. The mechanisms leading to this have not been determined. Nevertheless, it has been hypothesised that on the one hand, Borrelia spirochetes that are in the midgut and/or those that are in other tick organs 
Table 1 Phenotypic traits modified by tick-borne pathogens in the main vectors of $B$. burgdorferi

\begin{tabular}{|c|c|c|c|c|c|}
\hline Modified trait & $\begin{array}{l}\text { Tick } \\
\text { species }^{a}\end{array}$ & Stage $^{b}$ & Pathogens $^{c}$ & Detailed effect & Reference \\
\hline \multirow[t]{10}{*}{ Questing activity } & Ip & A & $B b$ & Walk shorter distances & {$[50,79]$} \\
\hline & Ip & $\mathrm{N}, \mathrm{A}$ & $B b$ & $\begin{array}{l}\text { Questing activity is increased but inhibited more importantly by } \\
\text { temperature }\end{array}$ & [80] \\
\hline & Ip & $N, A$ & $B b$ & Questing triggered by higher temperature and lower relative humidity & [66] \\
\hline & Ip & A & $B b$ & Reach higher questing height, walk slower & [52] \\
\hline & Ip & A & TBEv & Walk faster, reach higher questing height, more tolerant of desiccation & [50] \\
\hline & Ir & $L, N, A$ & $B b$ & Walk shorter distances & [81] \\
\hline & Ir & N & $B b$ & Walk less, stay in a relatively dry environment & [53] \\
\hline & Ir & A & TBEv & Walk faster, more tolerant to tick-repellent & [82] \\
\hline & Is & $\mathrm{N}$ & $B b$ & $\begin{array}{l}\text { Walk longer distances, reach higher questing height, attracted by vertical } \\
\text { surfaces }\end{array}$ & [51] \\
\hline & Is & A & $B b$ & $\begin{array}{l}\text { Walk shorter distances, reach lower questing height, avoid vertical } \\
\text { surfaces }\end{array}$ & [51] \\
\hline \multirow{5}{*}{$\begin{array}{l}\text { Survival \& energy } \\
\text { reserves }\end{array}$} & Ip, Ir & A & $B b$ & Prolonged survival & [67] \\
\hline & Ir & $\mathrm{N}, \mathrm{A}$ & $B b$ & Increased survival under desiccating conditions & [56] \\
\hline & Ir & $\mathrm{N}$ & $B b$ & Higher energy reserves (fat content) & [61] \\
\hline & Is & $\mathrm{N}$ & $A p$ & Increased survival under cold conditions & [55] \\
\hline & Is & $\mathrm{N}$ & $B m$ & Increased blood meal size & [63] \\
\hline
\end{tabular}

Ip, I. persulcatus; Ir, I. ricinus; Is, I. scapularis.

${ }^{\mathrm{b}} \mathrm{L}$, larvae; $\mathrm{N}$, nymphs; $\mathrm{A}$, adults.

${ }^{C} A p$, A. phagocytophilum; Bm, B. microti; Bb, B. burgdorferi s.l.; TBEv, TBE virus.

$[57,58]$ might change the physiology and/or metabolism of organs involved in water sorption, storage, or loss. Similarly to A. phagocytophilum, Borrelia spirochetes have also been described to change gene expression in ticks. In fact, Ramamoorthy et al. [59] reported the increased expression of one gene in B. burgdorferi-infected I. scapularis salivary glands during blood feeding. Expression modifications of genes involved in the maintenance of water in ticks would result in enhanced water storage in infected ticks, and the dependence of $I$. ricinus on humidity might therefore be reduced by Borrelia infection. It may also be hypothesized that spirochetes, which are known to change their gene expression according to temperature [60], might be able to modify tick gene expression under varying temperature conditions as well, inactivating genes that govern non-vital functions in the tick, slowing down metabolism in such a way that energy resources would essentially be devoted to resistance to unfavourable conditions, while maintaining favourable living conditions for spirochetes. Since it is known that spirochetes are non-infectious in unfed ticks [8] the switch-off of spirochete infection factors in unfed ticks might also trigger tick metabolism to slow down, explaining infected ticks better survival under challenging weather conditions. The chance of pathogen transmission is increased by better survival of infected ticks, giving the latter more time and opportunities to find a vertebrate host (and thereby transmit the spirochetes) under unfavourable conditions. On the other hand, these findings might be explained by modifications of tick behaviour by spirochetes, so that infected ticks take more risks by staying immobile under desiccating conditions, although usually $I$. ricinus ticks are known to show increased movement under such conditions [18,20]. Such risky behaviour would be beneficial to infected ticks, as they would spare energy reserves while uninfected ticks would deplete their reserves trying to find a moister environment without success, resulting in a higher death rate of more active uninfected ticks.

\section{Fat content in ticks}

According to some of the aforementioned observations, Borrelia-infected ticks are more tolerant of desiccating conditions (with a lower need to rehydrate, better survival and increased questing time under these conditions) than uninfected ticks. Since high desiccation forces $I$. ricinus ticks to consume more energy by moving down the vegetation to rehydrate more frequently $[21,29,32]$, the observed higher tolerance to desiccation in infected ticks could be due to their higher energy reserves (more fat). This has recently been observed; $I$. ricinus ticks that are infected by Borrelia contain more fat than uninfected individuals and thus have higher energy reserves [61]. For an average body size of 66.4 $\mu \mathrm{g}$, 
the mean fat content of an infected tick is $12.1 \%$ higher than that of an uninfected one. Bioenergetic calculations have shown that Borrelia spirochetes consume a negligible fraction of the tick energy reserves to grow [61]. In fact, under anaerobic conditions the energy required to grow a median population of 3,410 spirochetes using glucose corresponded to $0.10 \%$ of the total fat reserves of the nymph. However, the study did not revealed how higher energy reserves in ticks and Borrelia infection are associated, as mechanisms causing this phenomenon are presumably multiple and interconnected. Hypotheses may nevertheless be formulated. Various processes may operate on tick-host interactions (quantity and quality of blood-meal). Borrelia spirochetes in the vertebrate host might suppress host immune responses resulting in increased blood meal size in the tick. This has been shown to occur in I. trianguliceps [62] and I. scapularis ticks [63] feeding on rodents infected by Babesia microti, a tick-borne protozoan known to be immunosuppressive (unlike B. burgdorferi). The increased blood meal size might be subsequently converted into more fat content in the tick. Spirochetes in the blood might change the quality of the blood by increasing glucose concentration in infected blood [64]. Alternatively, Borrelia spirochetes might influence tick physiology (blood digestion and/or moulting process) by changing the expression of genes involved in fat storage in ticks (such as the $4 E-B P$ genes described by Kume et al. [65]) so that fat storage is enhanced during/after the blood meal. Spirochetes may also alter the behaviour of ticks in a way that reduces energy consumption by reducing ticks movements in infected ticks $[51,53,66]$. Although causes leading to such a phenomenon (i.e. higher fat content in infected ticks) remain unknown, its consequences are easy to imagine. In all these cases, the pathogen increases its transmission chances by increasing its vector energy reserves, thereby extending its vector lifespan. This might be an explanation for the longer life span of Borrelia-infected I. ricinus and $I$. persulcatus ticks under laboratory conditions reported by Naumov [67]. Moreover, higher energy reserves in Borrelia-infected ticks allow more time for questing. Since Borrelia-infected ticks can move up and down the vegetation more often until their fat reserves are depleted, they survive longer and questing time is increased. In turn, longer questing time results in ticks harbouring $B$. burgdorferi spirochetes having more chances to find hosts, therefore making spirochete transmission more likely. In short, this situation illustrates that a pathogen may modify the phenotypic traits of its tick vector to enhance its transmission to another host: by increased tolerance to desiccation, increased tick survival under desiccating conditions, and higher energy reserves, eventually leading to increased opportunities for its vector to find a host.

\section{Conclusions}

The idea that B. burgdorferi s.l. infection increases the opportunities that $I$. ricinus has to find a vertebrate host due to modified questing activity is particularly interesting. Faulde and Robbins [68] have reported that host-finding efficacy is increased in female $I$. ricinus ticks harbouring $B$. burgdorferi spirochetes. These authors have observed that Borrelia infection prevalence is higher in unfed ticks collected from clothing of volunteers than in unfed ticks collected directly from vegetation in the same forest in Germany. In the context of climate change, if weather conditions become warmer and drier (which is expected to favour Borrelia-infected I. ricinus ticks according to these findings), it can be surmised that the risk for human population to encounter ticks harbouring B. burgdorferi spirochetes, and therefore to be bitten by such individuals, might increase. As Lyme borreliosis is to date the most frequent tick-borne disease in the Northern hemisphere, accounting for approximately 85,500 new human cases annually, among which roughly 65,500 occur in Europe [69], we might expect this disease to become a greater public health concern if desiccating conditions become more pronounced and Borrelia-infected ticks are more likely to find hosts under such conditions. However, such suppositions might prove to be inaccurate in the future since Lyme borreliosis epidemiology does not depend solely on $I$. ricinus but rather on multiple parameters, notably Borrelia reservoir-host populations, which might be negatively influenced by climate change.

Competing interests

The authors declare that they have no competing interests.

Authors' contributions

$\mathrm{CH}$ researched the literature and wrote the first draft of the manuscript as a part of her PhD thesis work. LG improved overall manuscript structure and rewrote parts of the manuscript. Both authors read and approved the final manuscript.

\section{Acknowledgements}

The authors are thankful to Jonathan Hamley for proof reading the manuscript and to the two reviewers for their comments.

Received: 2 July 2014 Accepted: 5 November 2014

Published online: 06 January 2015

References

1. Moore J: Parasites and the Behaviour of Animals. New York: Oxford University Press; 2002.

2. Poulin R: Parasite manipulation of host behavior: an update and frequently asked questions. In Advances in the Study of Behavior. Edited by Brockmann HJ. Burlington: Academic Press; 2010:151-186.

3. Moore J: Parasites and the behavior of biting flies. J Parasito/ 1993, 79:1-16.

4. Hurd $\mathrm{H}$ : Manipulation of medically important insect vectors by their parasites. Annu Rev Entomol 2003, 48:141-161.

5. Lefèvre T, Thomas F: Behind the scene, something else is pulling the strings: emphasizing parasitic manipulation in vector-borne diseases. Infect Genet Evol 2008, 8:504-519.

6. Gern L: Life cycle of Borrelia burgdorferi sensu lato and transmission to humans. In Lyme Borreliosis. Edited by Lipsker D, Jaulhac B. Basel: Karger; 2009:18-30.

7. Kahl O, Janetzi-Mittmann C, Gray JS, Jonas R, Stein J, De Boer R: Risk of infection with Borrelia burgdorferi sensu lato for a host in relation to the 
duration of nymphal Ixodes ricinus feeding and the method of tick removal. Zbl Bakt 1998, 287:41-52.

8. Crippa M, Rais O, Gern L: Investigations on the mode and dynamics of transmission and infectivity of Borrelia burgdorferi sensu stricto and Borrelia afzelii in Ixodes ricinus ticks. Vector-Borne Zoonot Dis 2002, 2:3-9.

9. Anderson JF: Epizootiology of Lyme borreliosis. Scand J Infect Dis 1991, 23:23-34.

10. Lees $A D$, Milne $A$ : The seasonal and diurnal activities of individual sheep ticks (Ixodes ricinus L.). Parasitology 1951, 41:189-208.

11. Lees AD: Water balance in Ixodes ricinus $\mathrm{L}$. and certain other species of ticks. Parasitology 1946, 37:1-20.

12. Knülle W, Rudolph D: Humidity relationships and water balance of ticks. In Physiology of Ticks. Edited by Obenchain FD, Galun R. Oxford: Pergamon Press; 1982:43-70.

13. Rudolph D, Knülle W: Mechanisms contributing to water balance in nonfeeding ticks and their ecological implications. In Recent Advances in Acarology. Edited by Rodriguez JG. New York: Academic Press; 1979:375-383.

14. Pugh PJ, King PE, Fordy MR: The spiracle of Ixodes ricinus (L.) (Ixodidae: Metastigmata: Acarina): a passive diffusion barrier for water vapour. Zool J Linn Soc 1988, 93:113-131.

15. Lighton JRB, Fielden $L$, Rechav Y: Discontinuous ventilation in a non-insect, the tick Amblyomma marmoreum (Acari: Ixodidae): characterization and metabolic modulation. J Exp Biol 1993, 180:229-245.

16. Kahl O, Alidousti I: Bodies of liquid water as a source of water gain for Ixodes ricinus ticks (Acari: Ixodidae). Exp Appl Acarol 1997, 21:731-746

17. Kröber T, Guerin PM: Ixodid ticks avoid contact with liquid water. J Exp Biol 1999, 202:1877-1883.

18. Lees AD: The sensory physiology of the sheep tick, Ixodes ricinus. J Exp Biol 1948, 25:145-207.

19. Needham GR, Teel PD: Off-host physiological ecology of ixodid ticks. Annu Rev Entomol 1991, 36:659-681.

20. Crooks E, Randolph SE: Walking by Ixodes ricinus ticks: intrinsic and extrinsic factors determine the attraction of moisture or host odour. J Exp Biol 2006, 209:2138-2142.

21. Perret $\mathrm{L}$, Guerin PM, Diehl PA, Vlimant M, Gern L: Darkness induces mobility, and saturation deficit limits questing duration, in the tick Ixodes ricinus. J Exp Biol 2003, 206:1809-1815.

22. Carroll JF, Mills GD Jr, Schmidtmann ET: Patterns of activity in host-seeking adult Ixodes scapularis (Acari: Ixodidae) and host-produced kairomones. J Med Entomol 1998, 35:11-15.

23. Dusbabek F, Daniel M, Cerny V: Stratification of engorged Ixodes ricinus larvae overwintering in soil. Folia Parasit 1971, 18:261-266

24. Daniel M, Cerny V, Dusbabek F: Overwintering of the tick Ixodes ricinus (L.) under conditions of a field experiment. Folia Parasit 1972, 19:305-314.

25. Gray JS: The development and seasonal activity of the tick Ixodes ricinus: a vector of Lyme borreliosis. Rev Med Vet Entomol 1991, 79:323-333.

26. Dautel H, Dippel C, Kämmer D, Werkhausen A, Kahl O: Winter activity of Ixodes ricinus in a Berlin forest. Int J Med Microbiol 2008, 298:50-54

27. Gray JS: Ixodes ricinus seasonal activity: implications of global warming indicated by revisiting tick and weather data. Int J Med Microbiol 2008, 298:19-24.

28. MacLeod J: Ixodes ricinus in relation to its physical environment. II. The factors governing survival and activity. Parasitology 1935, 27:123-144.

29. Perret $J L$, Guigoz E, Rais $O$, Gern L: Influence of saturation deficit and temperature on Ixodes ricinus tick questing activity in a Lyme borreliosisendemic area (Switzerland). Parasitol Res 2000, 86:554-557.

30. Randolph SE, Green RM, Hoodless AN, Peacey MF: An empirical quantitative framework for the seasonal population dynamics of the tick Ixodes ricinus. Int J Parasitol 2002, 32:979-989.

31. Perret $\mathrm{J}$, Rais O, Gern L: Influence of climate on the proportion of Ixodes ricinus nymphs and adults questing in a tick population. J Med Entomol 2004, 41:361-365.

32. Randolph SE, Storey K: Impact of microclimate on immature tick-rodent interactions (Acari: Ixodidae): implications for parasite transmission. J Med Entomol 1999, 36:741-748.

33. Burri C, Morán Cadenas F, Douet V, Moret J, Gern L: Ixodes ricinus density and infection prevalence with Borrelia burgdorferi sensu lato along a north-facing altitudinal gradient in the Rhône Valley (Switzerland). Vector-Borne Zoonot Dis 2007, 7:50-58.

34. Morán Cadenas F, Rais O, Jouda F, Douet V, Humair PF, Moret J, Gern L: Phenology of Ixodes ricinus and infection with Borrelia burgdorferi sensu lato along a North- and South-facing altitudinal gradient on Chaumont Mountain, Switzerland. J Med Entomol 2007, 44:683-693.

35. Gern L, Morán Cadenas F, Burri C: Influence of some climatic factors on Ixodes ricinus ticks studied along altitudinal gradients in two geographic regions in Switzerland. Int J Med Microbiol 2008, 298:55-59.

36. Lindgren $\mathrm{E}$, Tälleklint $\mathrm{L}$, Polfeldt T: Impact of climatic change on the northern latitude limit and population density of the diseasetransmitting European tick Ixodes ricinus. Environ Health Persp 2000, 108:119-123.

37. Jaenson TGT, Jaenson DGE, Eisen L, Petersson E, Lindgren E: Changes in the geographical distribution and abundance of the tick Ixodes ricinus during the past 30 years in Sweden. Parasit Vectors 2012, 5:8.

38. Jore S, Viljugrein H, Hofshagen M, Brun-Hansen H, Kristoffersen AB, Nygard K, Brun E, Ottesen P, Saevik BK, Ytrehus B: Multi-source analysis reveals latitudinal and altitudinal shifts in range of Ixodes ricinus at its northern distribution limit. Parasit Vectors 2011, 4:84.

39. Daniel M, Danielova V, Kriz B, Jirsa A, Nozicka J: Shift of the tick Ixodes ricinus and tick-borne encephalitis to higher altitudes in central Europe. Eur J Clin Microbiol Infect Dis 2003, 22:327-328.

40. Materna J, Daniel M, Danielova V: Altitudinal distribution limit of the tick Ixodes ricinus shifted considerably towards higher altitudes in central Europe: results of three years monitoring in the Krkonose Mts (Czech Republic). Cent Eur J Public Health 2005, 13:24-28.

41. Materna J, Daniel M, Metelka L, Harcarik J: The vertical distribution, density and the development of the tick /xodes ricinus in mountain areas influenced by climate changes (The Krkonose Mts., Czech Republic). Int J Med Microbiol 2008, 298:25-37.

42. Jaenson TGT, Lindgren E: The range of Ixodes ricinus and the risk of contracting Lyme borreliosis will increase northwards when the vegetation period becomes longer. Ticks Tick Borne Dis 2011, 2:44-49.

43. Danielova V, Rudenko N, Daniel M, Holubova J, Materna J, Golovchenko M, Schwarzova L: Extension of Ixodes ricinus ticks and agents of tick-borne diseases to mountain areas in the Czech Republic. Int J Med Microbiol 2006, 296:48-53.

44. Lehane MJ: Managing the blood meal. In Biology of Blood-Sucking Insects. 2nd edition. New York: Cambridge University Press; 1991:84-115.

45. Tarnowski B, Coons LB: Ultrastructure of the midgut and blood meal digestion in the adult tick Dermacentor variabilis. Exp Appl Acarol 1989, 6:263-289.

46. Umemiya-Shirafuji R, Matsuo T, Liao M, Boldbaatar D, Battur B, Suzuki $H$, Fujisaki K: Increased expression of ATG genes during nonfeeding periods in the tick Haemaphysalis longicornis. Autophagy 2010, 6:473-481.

47. Sonenshine DE: Biology of Ticks. New York: Oxford University Press; 1991.

48. Steele GM, Randolph SE: An experimental evaluation of conventional control measures against the sheep tick, Ixodes ricinus (L.) (Acari: Ixodidae). I. A unimodal seasonal activity pattern. B Entomol Res 1985, 75:489-499.

49. Van Es RP, Hillerton JE, Gettinby G: Lipid consumption in Ixodes ricinus (Acari: Ixodidae): temperature and potential longevity. B Entomol Res 1998, 88:567-573.

50. Alekseev AN: Tick pathogen interactions: behavior of infected and uninfected ticks (Ixodidae). In Acarology. Edited by Mitchell R, Horn DJ, Needham GR, Welbourn WC. Columbus: Biological Survey; 1996:113-115.

51. Lefcort $H$, Durden LA: The effect of infection with Lyme disease spirochetes (Borrelia burgdorferi) on the phototaxis, activity, and questing height of the tick vector Ixodes scapularis. Parasitology 1996, 113:97-103.

52. Romashchenko AV, Ratushnyak AS, Zapara TA, Tkachev SE, Moshkin MP: The correlation between tick (Ixodes persulcatus Sch.) questing behaviour and synganglion neuronal responses to odours. J Insect Physiol 2012, 58:903-910

53. Herrmann C, Gern L: Do level of energy reserves, hydration status and Borrelia infection influence walking by Ixodes ricinus (Acari: Ixodidae) ticks? Parasitology 2012, 139:330-337.

54. Herrmann C, Gern L: Survival of Ixodes ricinus (Acari: Ixodidae) nymphs under cold conditions is negatively influenced by frequent temperature variations. Ticks Tick Borne Dis 2013, 4:445-451.

55. Neelakanta G, Sultana H, Fish D, Anderson JF, Fikrig E: Anaplasma phagocytophilum induces /xodes scapularis ticks to express an antifreeze glycoprotein gene that enhances their survival in the cold. I Clin Invest 2010, 120:3179-3190. 
56. Herrmann C, Gern L: Survival of Ixodes ricinus (Acari: Ixodidae) under challenging conditions of temperature and humidity is influenced by Borrelia burgdorferi sensu lato infection. J Med Entomol 2010, 47:1196-1204.

57. Burgdorfer W, Hayes SF, Corwin D: Pathophysiology of the Lyme disease spirochete, Borrelia burgdorferi, in Ixodid ticks. Rev Infect Dis 1989, 11:1142-1450.

58. Lebet N, Gern L: Histological examination of Borrelia burgdorferi infections in unfed Ixodes ricinus nymphs. Exp Appl Acarol 1994, 18:177-183.

59. Ramamoorthi N, Narasimhan S, Pal U, Bao F, Yang XF, Fish D, Anguita J, Norgard MV, Kantor FS, Anderson JF, Koski RA, Fikrig E: The Lyme disease agent exploits a tick protein to infect the mammalian host. Nature 2005, 436:573-577.

60. Ojaimi C, Brooks C, Casjens S, Rosa P, Elias A, Barbour A, Jasinskas A, Benach J, Katona L, Radolf J, Casimano M, Skare J, Swingle K, Atkins D, Schwartz I: Profiling of temperature-induced changes in Borrelia burgdorferi gene expression by using whole genome arrays. Inf Immun 2003, 71:1689-1705.

61. Herrmann C, Voordouw MJ, Gern L: Ixodes ricinus ticks infected with causative agent of Lyme disease, Borrelia burgdorferi sensu lato, have higher energy reserves. Int J Parasitol 2013, 43:477-483.

62. Randolph SE: The effect of Babesia microti on feeding and survival in its tick vector, Ixodes trianguliceps. Parasitology 1991, 102:9-16.

63. Hu R, Hyland KE, Markowski D: Effects of Babesia microti infection on feeding pattern, engorged body weight, and molting rate of immature Ixodes scapularis (Acari: Ixodidae). J Med Entomol 1997, 34:559-564.

64. Norte AC, Lobato DC, Braga E, Antonelli Y, Lacorte G, Félix GM, Gonçalves M, Lopes de Carvalho I, Gern L, Núncio MS, Ramos JA, Lopes De Carvalho I, Gern L, Núncio MS, Ramos JA: Do ticks and Borrelia burgdorferi s.l. constitute a burden to birds? Parasitol Res 2013, 112:1903-1912.

65. Kume A, Baldbaatar D, Takazawa Y, Umemiya-Shirafuji R, Tanaka T, Fujisaki K: RNAi of the translation inhibition gene $4 E-B P$ identified from the hard tick, Haemaphysalis longicornis, affects lipid storage during the off-host starvation period of ticks. Parasitol Res 2012, 111:889-896.

66. Alekseev AN, Dubinina HV: Abiotic parameters and diel seasonal activity of Borrelia-infected and uninfected Ixodes persulcatus (Acarina: Ixodidae). J Med Entomol 2000, 37:9-15.

67. Naumov RL: Longevity of forest and taiga ticks (Ixodidae) infected and noninfected with Borrelia burgdorferi groups. Parazitologiya 2003, 37:527-532.

68. Faulde MK, Robbins RG: Tick infestation and Borrelia burgdorferi s.l. infection-induced increase in host-finding efficacy of female Ixodes ricinus under natural conditions. Exp Appl Acarol 2008, 44:137-145.

69. Hubalek Z: Epidemiology of Lyme borreliosis. In Lyme Borreliosis. Edited by Lipsker D, Jaulhac B. Basel: Karger; 2009:31-50.

70. Matuschka FR, Fischer P, Musgrave K, Richter D, Spielman A: Hosts on which nymphal Ixodes ricinus most abundantly feed. Am J Trop Med Hyg 1991, 44:100-107.

71. Humair PF, Gern L: Relationship between Borrelia burgdorferi sensu lato species, red squirrels (Sciurus vulgaris) and Ixodes ricinus in enzootic areas in Switzerland. Acta Trop 1998, 69:213-227.

72. Humair PF, Rais O, Gern L: Transmission of Borrelia afzelii from Apodemus mice and Clethrionomys voles to Ixodes ricinus: differential transmission pattern and overwintering maintenance. Parasitology 1999, 118:33-42.

73. Hanincova K, Schäfer SM, Etti S, Sewell HS, Taragelova V, Ziak D, Labuda M, Kurtenbach K: Association of Borrelia afzelii with rodents in Europe. Parasitology 2003, 126:11-20.

74. Morán Cadenas F, Rais O, Humair PF, Douet V, Moret J, Gern L: Identification of host bloodmeal source and Borrelia burgdorferi sensu lato in field-collected Ixodes ricinus ticks in Chaumont (Switzerland). J Med Entomol 2007, 44:1109-1117.

75. Jaenson TGT, Tälleklint L: Incompetence of roe deer as reservoirs of the Lyme disease spirochete. J Med Entomol 1992, 29:813-817.

76. Mejlon HA, Jaenson TGT: Questing behaviour of Ixodes ricinus ticks (Acari: Ixodidae). Exp Appl Acarol 1997, 21:747-754.

77. Gigon F: Biologie d'lxodes ricinus L. sur le Plateau Suisse - une contribution à l'écologie de ce vecteur, PhD thesis. University of Neuchâtel, Biology Department; 1985. http://doc.rero.ch/search?In=fr\&sc=1\&p=Gigon\&action_ search $=$

78. Belozerov VN: Diapause and biological rythms in ticks. In Physiology of Ticks. Edited by Obenchain FD, Galun R. Oxford: Pergamon Press; 1982:469-500

79. Alekseev AN, Dubinina HV: Symbiotic relationships in the complex carrierpathogen system. Dokl Akad Nauk 1994, 338:259-261.
80. Naumov RL: The exploratory activity of the Borrelia-infected taiga tick Ixodes persulcatus. Parazitologiya 1999, 33:251-256

81. Alekseev AN, Jensen PM, Dubinina HV, Smirnova LA, Makrouchina NA, Zharkov SD: Peculiarities of behaviour of taiga (Ixodes persulcatus) and sheep (Ixodes ricinus) ticks (Acarina: Ixodidae) determined by different methods. Folia Parasit 2000, 47:147-153.

82. Belova OA, Burenkova LA, Karganova GG: Different tick-borne encephalitis virus (TBEV) prevalences in unfed versus partially engorged ixodid ticks evidence of virus replication and changes in tick behavior. Ticks Tick Borne Dis 2012, 3:240-246.

\section{Submit your next manuscript to BioMed Central and take full advantage of:}

- Convenient online submission

- Thorough peer review

- No space constraints or color figure charges

- Immediate publication on acceptance

- Inclusion in PubMed, CAS, Scopus and Google Scholar

- Research which is freely available for redistribution

Submit your manuscript at www.biomedcentral.com/submit
C Biomed Central 